\title{
DESENVOLVIMENTO ECONÔMICO, EQUILÍBRIO AMBIENTAL E ÉTICA: DESAFIOS JURÍDICOS E FILOSÓFICOS NO (DO) SÉC. XXI.
}

\section{ECONOMIC DEVELOPMENT, ENVIRONMENTAL BALANCE AND ETHICS: JURIDICAL AND PHILOSOPHICAL CHALLENGES OF THE $21^{\text {st }}$ CENTURY.}

\author{
${ }^{1}$ José Flôr de Medeiros Júnior \\ ${ }^{2}$ Hertha Urquiza Baracho
}

\section{RESUMO}

A Constituição brasileira tem como alicerce a dignidade da pessoa humana esculpido no Art. $1^{\circ}$, III. A Lei Maior, no supracitado título, Art. $3^{\circ}$, II, preceitua como um dos objetivos garantir o desenvolvimento nacional. O Art. 225/CRFB/88, Caput, afirma a existência do direito ao meio ambiente ecologicamente equilibrado enquanto direito fundamental com escopo na dignidade da pessoa humana e posto o mesmo como direito difuso, transindividual, intergeracional e essencial à sadia qualidade de vida. Impõem-se, assim, a discussão sobre desenvolvimento econômico, equilíbrio ambiental, ética, sustentabilidade e direito ao exposto no Art. 225/CRFB/88.

Palavras-chave: Desenvolvimento econômico; dignidade da pessoa humana; equilíbrio ambiental; sustentabilidade; ética.

\begin{abstract}
Brazilian Constitution is based on the idea of human dignity as stated in Art. $1^{\text {st }}$, III. In Art $3^{\text {rd }}$, II, it underlines national development as a goal to be achieved. Art. 225/CRFB/88, Caput, focus on the right to an ecologically balanced environment as a fundamental right linked to the idea of human dignity, seen as a diffuse, transidividual and intergenerational right, essential to healthy life standards. Thus, we superimpose a discussion on economic development, environmental balance, ethics, sustainability and law to the legal precepts exposed on Art. 225/CRFB/88.
\end{abstract}

Keywords: Economic development; human dignity; environmental balance; sustainability; ethics.

\footnotetext{
${ }^{1}$ Graduado em Direito pela Faculdade de Ciências Sociais e Aplicadas - FACISA, (Brasil). Professor de Direito Constitucional e Direito Ambiental da Faculdade Maurício de Nassau - UNINASSAU, Campina Grande, (Brasil). E-mail: jfmjmedeiros@gmail.com

${ }^{2}$ Doutora em Direito pela Pontifícia Universidade Católica - PUC, São Paulo, (Brasil). Pós-Doutorado em Ciências Sociais Aplicadas (Università degli Studi di Firenze - UNIFI). Professora de Direito Econômico no Centro Universitário de João Pessoa - UNIPÊ, Paraíba. E-mail: herthaurquiza@ gmail.com
} 


\section{INTRODUÇÃO}

A Constituição da República Federativa do Brasil (CRFB/88) tem entre seus fundamentos a dignidade da pessoa humana. Tal construto teórico faz parte do Título I,

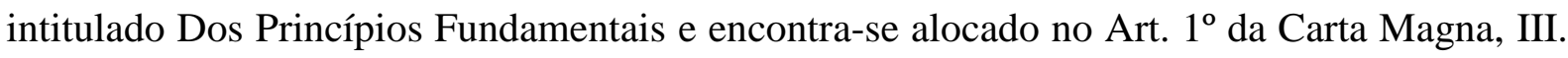
O texto constitucional, no supracitado título, em seu Art. $3^{\circ}$, II, preceitua como um dos objetivos constitucionais garantir o desenvolvimento nacional.

O Art. 225 da Carta Magna afirma em seu Caput a existência do direito a um meio ambiente ecologicamente equilibrado enquanto direito fundamental com escopo no princípio da dignidade da pessoa humana. Posto o meio ambiente como direito difuso, transindividual e intergeracional e essencial à sadia qualidade de vida do cidadão.

No esteio dos alicerces do texto da Constituição Federal de 1988 a preservação do meio ambiente é caminho para a valorização do ser humano. Ocorre, entretanto, ser necessária a discussão sobre a relação existente entre desenvolvimento econômico, equilíbrio ambiental, ética, sustentabilidade e o direito fundamental ao meio ambiente ecologicamente equilibrado enquanto espaço de (sobre) vivência do Ser Humano.

A existência de uma distância entre a previsão constitucional e a concretização dos fundamentos constitucionais constantes do Art. 1\%CRFB/88 e dos objetivos esculpidos pelo constituinte originário no Art. $3^{\circ}$ da Lei Maior. A não observância dos fundamentos e objetivos constitucionais termina por comprometer, não somente a efetivação dos Direitos Fundamentais, mas todo o conjunto de direitos positivados na Carta Magna. Neste sentido verifica-se a impossibilidade dos direitos fundamentais, positivados que foram, serem efetivados. Urge, desta forma, aprofundar a discussão entre a imprescindibilidade do desenvolvimento econômico que somente podemos entende-lo na forma sustentável.

A temática proposta perpassa, então, pelo questionamento: é possível a existência de um direito ao desenvolvimento econômico sem a existência de um meio ambiente ecologicamente equilibrado? O que nos obriga a um segundo questionamento: Sem o direito fundamental ao meio ambiente ecologicamente equilibrado é possível falar em sustentabilidade no Brasil?

Problema que se impõe pela própria força do termo direito e ganha espaço quando vem à tona a existência de um direito ao desenvolvimento econômico a ser discutido dissociado de políticas de sustentabilidade e de um meio ambiente ecologicamente 
equilibrado. Percebe-se, neste ponto, o embate a ocorrer no terreno legal à necessária materialização dos princípios postos como norteadores do texto constitucional brasileiro em relação ao desenvolvimento econômico e ao meio ambiente.

Postas estas notas preliminares sobre o tema e o objeto de estudo, tem-se como propósito deste o de analisar a possibilidade de efetividade do meio ambiente ecologicamente equilibrado como elemento essencial para a consecução do direito ao desenvolvimento econômico e da sustentabilidade.

Para tanto será primordial investigar o direito ao desenvolvimento econômico nacional enquanto objetivo inserido na Constituição Federal de 1988 e atrelado ao meio ambiente; discutir a efetivação do direito fundamental ao meio ambiente ecologicamente equilibrado como alicerce ao desenvolvimento econômico; estabelecer a importância de um debate sobre a sustentabilidade e a ética no campo do Direito.

Abalizado no diálogo entre o Direito Constitucional, Direito Ambiental, Direito Econômico, Desenvolvimento Econômico, Sustentabilidade, Economia Ambiental, História Ambiental, Filosofia do Direito e Direitos Fundamentais. O caminho metodológico traçado objetivando a realização deste será o da pesquisa bibliográfica e documental enquanto espaço à construção de uma análise situada no método hermenêutico e fazendo uso da interpretação judicial-histórica com a utilização de dados que serão coletados no emprego da leitura relacionada à legislação e doutrinas relacionadas ao tema em comento.

No concernente à relevância teórica-acadêmica e social o trabalho procura (re) estabelecer novos diálogos de forma a (re) construir caminhos na elaboração de (novas) respostas aos (novos) problemas advindos do tecido social e que estão de décadas a questionar o mundo jurídico. Procurando, assim, construir nova reflexão sobre o tema desterritorializando-o dos saberes institucionalizados no interior do Direito positivo e pensado como Ciência.

Por fim, este tem como um de seus alicerces o diálogo mediado pelo meio ambiente ecologicamente equilibrado, conforme preceitua a Lei Fundamental em seu Art. 225, Caput, conforme esteio ao desenvolvimento econômico nacional e a sustentabilidade em sua relação direta com a ética. Percebe-se, assim, ser este um dos caminhos para o (re) estabelecimento à cidadania historicamente perdida ao tempo que encaminha o homem à percepção da importância do reconhecimento da dignidade da pessoa humana enquanto fundamento 
constitucional pátrio. Discutir-se-á, ainda, a importância de um novo homem a perceber na prática cidadã um dos caminhos à construção da sustentabilidade.

\section{DIREITO AO DESENVOLVIMENTO ECONÔMICO E AO EQUILÍBRIO AMBIENTAL}

A discussão sobre o desenvolvimento econômico deve considerar os fundamentos e objetivos constitucionais. Os alicerces constitucionais existentes no Art. $1^{\circ}$, II, III e IV da Constituição da República Federativa do Brasil de 1988 e os objetivos postos no Art. $3^{\circ}$, II e III do diploma legal supracitado devem ser considerados ao enfrentarmos tal problemática teórica. Necessário será, ainda, nos situarmos no Título VII, intitulado da Ordem Econômica e Financeira em seu Capítulo I, nomeado de Dos Princípios Gerais da Atividade Econômica especificamente no que preceitua o Art. 170, VI da Lei Maior. E, ainda, o exposto no Art. 225 da Carta Magna.

Destarte o preceituado no texto constitucional é necessário entender que a problemática ambiental não deve ser considerada como uma situação a ser resolvida apenas no âmbito local, regional ou nacional. $\mathrm{O}$ objetivo de superação da problemática ambiental à ótica do desenvolvimento econômico e na procura de um equilíbrio ambiental está na ordem jurídica mundial e é, portanto, global. Ocorre, entretanto, que a questão ambiental tem raízes mais profundas fincadas no avanço da produção econômica no interior do processo capitalista de produção.

E é neste sentido, histórico, que E. P. Thompson (1998) ao discorrer sobre o processo da Revolução Industrial na Inglaterra e as modificações econômicas, políticas, sociais e culturais advindas com o supracitado processo afirmou que "não existe desenvolvimento econômico que não seja ao mesmo tempo desenvolvimento ou mudança de uma cultura. " (THOMPSON, 1998, p. 304). Por este ângulo é necessário perceber a importância posta pelo historiador inglês sobre o impacto das modificações econômicas em relação à sociedade no âmbito da cultura.

Ademais, o embate teórico sobre crescimento e desenvolvimento deve ser posto na esfera legal e doutrinária com base nos fundamentos e objetivos constitucionais. Outro ponto a ser considerado são os interesses da população envolvida, e não escutada em tal diálogo, de forma que possamos caminhar à superação da crise ambiental instaurada a partir do uso 
irracional dos recursos naturais por parte do homem ao desconsiderar a finitude destes. A afirmativa posta por Sachs (2005) de que "a maior tragédia de nosso tempo é que um sexto da humanidade nem está na escala do desenvolvimento" (SACHS, 2005, p. 46) é sintomática em relação à temática em comento.

Afinal, um sexto da humanidade não é escutado, nem tem voz, sobre seus próprios destinos. São considerados, em tese, como a residir na escala do crescimento econômico e, sendo assim, suas necessidades serem mais imediatas se comparadas com populações a residirem no território do desenvolvimento. $\mathrm{Na}$ mesma linha de raciocínio escreve Veiga (2015) ao expor que "todas as noites entre um terço e metade da humanidade costuma ir para a cama com fome." (VEIGA, 2015, p. 49)

A equação, vê-se, não é tão simples como aponta Sen (2010) alegando que

uma concepção adequada de desenvolvimento deve ir muito além da acumulação de riqueza e do crescimento do Produto Nacional Bruto e de outras variáveis relacionadas à renda. Sem desconsiderar a importância do crescimento econômico, precisamos enxergar muito além dele. (SEN, 2010, 28)

Pugna-se, portanto, por modificações no campo da cultura cidadã sob pena de não conseguirmos avançar em busca de um equilíbrio ambiental como elemento posto à realização do desenvolvimento econômico em sua vertente sustentável e sem desconsiderar o desenvolvimento político, social e cultural. Por esta ótica afirmam Thomas \& Callan (2014) que

\footnotetext{
“as metas de qualidade ambiental, o desenvolvimento sustentável e a biodiversidade estabelecem uma ambiciosa agenda. Isso significa que toda a sociedade deve trabalhar em direção ao desenvolvimento de iniciativas efetivas para a criação de políticas ambientais. E no centro desses esforços está o processo de planejamento no qual agentes públicos, indústria e cidadãos comuns participam." (THOMAS \& CALLAN, 2014, p. 27)
}

Ocorre que a ideia de cidadão no Brasil contemporâneo precisa ser resgatada e aqui estamos ancorados na filosofia alemã, especificamente em Kant (2008), quando discute sobre a noção de esclarecimento e expõe, de forma imperiosa que

a saída do homem de sua menoridade, da qual o culpado é ele próprio. A menoridade é a incapacidade de fazer uso de seu entendimento sem a direção de outro indivíduo. O homem é o próprio culpado dessa menoridade se a sua causa não estiver na ausência de entendimento, mas na ausência de decisão e coragem de servir-se de si mesmo sem a direção de outrem. Sapere aude! Tem a ousadia 
de fazer uso de teu próprio entendimento - tal é o lema do Esclarecimento. (aufklurung) (KANT, 2008, 115)

Ao discutirmos o exposto por Thomas \& Callan em conjunto com o pensamento kantiano encontramos um primeiro obstáculo em relação a realização do preceituado no Art. $3^{\circ}$, II da Constituição Federal. Existe uma impossibilidade concreta de realização do desenvolvimento nacional por inexistência da cidadania na prática cotidiana. Reside a mesma, posta enquanto fundamento da Lei Maior em seu Art. $1^{\circ}$, II. A modificação cultural, a qual fizemos referência ao nos ancorarmos no pensamento de E. P. Thompson, o cidadão a participar das metas de qualidade ambiental de Thomas \& Callan e o homem a residir na menoridade kantiana e que insiste em não atingir a maioridade são situações que o Brasil, em sua particularidade como nação e Estado, deve resolver primeiro para começar a galgar os degraus do desenvolvimento econômico nacional sustentável.

$\mathrm{Na}$ escrita literal do Art. $3^{\circ}$, II da Constituição Federal vem o desenvolvimento nacional a ser um dos objetivos da República Federativa do Brasil, assim como a erradicação da pobreza e a redução das desigualdades sociais e regionais conforme texto constitucional, Art. $3^{\circ}$, III/CRFB/88. A ausência de cumprimentos aos fundamentos constitucionais, bem como dos objetivos constitucionais termina por propiciar uma leitura desconexa entre os fundamentos esculpidos no Art. 1\%CRFB/88 e os objetivos a ter guarita no Art. $3^{\circ}$ do diploma legal supracitado.

Em outras palavras, estamos a afirmar da impossibilidade concreta de realização do direito ao desenvolvimento sem que haja por parte do Estado a criação da estrutura mínima para concretização do fundamento constitucional da cidadania.

A situação é mais grave quando direcionamos nosso olhar para o Art. $1^{\circ}$, III da Constituição Federal. Ou seja, a dignidade da pessoa humana. O fundamento constitucional da dignidade da pessoa humana não tem como ser concretizado sem que todos, indistintamente, possuam o direito à sadia qualidade de vida que somente pode ser alcançada através do direito ao desenvolvimento econômico nacional sustentável. Por este prisma é de reconhecer o exposto por Sarlet (2015) ao afirmar que

assim, quando se fala - no nosso sentir equivocadamente - em direito à dignidade, se está, em verdade, a considerar o direito a reconhecimento, respeito, proteção e até mesmo promoção e desenvolvimento da dignidade, podendo inclusive falar-se de um direito a uma existência digna, sem prejuízo de outros 
sentidos que se possa atribuir aos direitos fundamentais relativos à dignidade da pessoa. (SARLET, 2015, p. 82)

E ainda que

\begin{abstract}
a qualificação da dignidade da pessoa humana como princípio fundamental traduz a certeza de que o artigo $1^{\circ}$, inciso III, de nossa Lei Fundamental não contém apenas (embora também e acima de tudo) uma declaração de conteúdo ético e moral, mas que constitui norma jurídico-positiva dotada, em sua plenitude, de status constitucional formal e material e, como tal, inequivocamente carregado de eficácia. (SARLET, 2015, p. 82)
\end{abstract}

Vê-se, portanto, que o fundamento maior do texto constitucional pátrio carrega consigo o direito à uma vida digna, à educação, à saúde, à moradia, a um meio ambiente ecologicamente equilibrado e, é claro, ao desenvolvimento econômico nacional sustentável e à sustentabilidade. Estamos, neste ponto, a olhar para o Art. $1^{\circ}$, II e III da Lei Maior descumpridos pelo Estado e pelos homens que habitam o território nacional. Cabe aqui uma explicação de por qual motivo utilizamos a expressão homens e não cidadãos. Para consubstanciar nosso posicionamento vamos nos referenciar em Aristóteles ao escrever que aquele "que não consegue viver em sociedade, ou que não necessita de nada porque se basta a si mesmo, não participa do Estado; é um bruto ou uma divindade. " (ARISTÓTELES, 2003, p. 15) A cidadania não é apenas algo positivado no texto constitucional. A cidadania precisa ser exercida pela, e para, própria existência constitucional do homem enquanto participe do Estado.

Impõe-se ao Estado, pelo comando normativo existente no fundamento da dignidade da pessoa humana, a criação de condições dignas ao exercício do direito à vida em seu duplo sentido: biológico e social. Mas cabe ao homem exercer a cidadania através de sua vivência plena na vida do Estado sob pena de não sair da menoridade kantiana e, ao mesmo tempo, referendar, com sua omissão, tudo aquilo imposto pelo Estado.

Por esta ótica vemos que o objetivo posto pelo constituinte originário no Art. $3^{\circ}$, III da Lei Fundamental Pátria é apenas uma meta traçada devido à ausência de práticas cidadãs, de reconhecimento da dignidade da pessoa humana e da não realização do desenvolvimento nacional que neste texto estamos a nomeá-lo de desenvolvimento econômico nacional sustentável. Nosso raciocínio, neste momento, comunga com o pensamento de Veiga (2015) quando aduz que "desenvolvimento tem a ver, primeiro e acima de tudo, com a possibilidade de as pessoas viverem o tipo de vida que escolherem, e com a provisão dos instrumentos e das 
oportunidades para fazerem suas escolhas. " (VEIGA, 2015, p. 82). Demanda-se, ainda, pelo exposto por Sen (2010) ao demonstrar que o desenvolvimento

\begin{abstract}
tem de estar relacionado sobretudo com a melhora da vida que levamos e das liberdades que desfrutamos. Expandir as liberdades que temos razão para valorizar não só torna nossa vida mais rica e mais desimpedida, mas também permite que sejamos seres sociais mais complexos, pondo em prática nossas volições, interagindo com o mundo em que vivemos e influenciando esse mundo. (SEN, 2010, 29)
\end{abstract}

Reforçando, assim, nossa argumentação de que inexiste uma possibilidade concreta de desenvolvimento no Brasil pela ausência de cidadania, embora existam as liberdades políticas. O não exercício da prática cidadã reforça o pensamento kantiano de que escolhemos residir na menoridade. Constate-se, ainda, o afirmado por Piovesan (2010) de que

\begin{abstract}
sem a efetividade dos direitos econômicos, sociais e culturais, os direitos civis e políticos se reduzem a meras categorias formais, enquanto, sem a realização dos direitos civis e políticos, ou seja, sem a efetividade da liberdade entendida em seu mais amplo sentido, os direitos econômicos e sociais carecem de verdadeira significação. Não há mais como cogitar da liberdade divorciada da justiça social, como também infrutífero pensar na justiça social divorciada da liberdade. Em suma, todos os direitos humanos constituem num complexo integral, único e indivisível, em que os diferentes direitos estão necessariamente interrelacionados e interdependentes entre si. (PIOVESAN, 2010, p. 43)
\end{abstract}

E por esta linha o exposto como objetivos constitucionais deve ser analisada à ótica da realização da justiça no âmbito social e visto na interconexão entre os fundamentos e objetivos constitucionais enquanto alicerces ao Art. 170, VI da Lei Fundamental. Consoante Nussbaum (2014) ao afirmar que "o que importa para a justiça é a qualidade de vida das pessoas. " (NUSSBAUM, 2014, p. 100).

Ao não avançarmos no desenvolvimento econômico nacional sustentável não estamos somente não atendendo um objetivo constitucional, mas negando direitos gravados pelo constituinte originário na Lei Fundamental. Estamos indo além, em sentido negativo, por estarmos a negar justiça social aos habitantes do solo pátrio ao tempo que pensamos avançar pelo simples crescimento do Produto Nacional Bruto.

\title{
1.1 Equilíbrio Ambiental: Uma Necessária Discussão
}


A proposta de discussão posta na elaboração deste não esteve, como fizemos exposição na Introdução, somente em torno de discutir o desenvolvimento versus crescimento econômico. Entendemos que o aludido embate não está perto de ser terminado e não é interesse nosso de esgotá-lo nestas páginas. Quiçá em outro momento.

O intuito foi, portanto, de correlacionar desenvolvimento econômico com a noção de equilíbrio ambiental para atingirmos um espaço de conversação sobre sustentabilidade e ética diante do necessário equilíbrio ambiental à (sobre) vivência humana.

Fiodor Dostoiévski, escritor russo do Séc. XIX, em um de seus textos da maturidade do autor, intitulado de $\mathrm{O}$ Adolescente, escreveu sobre transformações sociais e econômicas que ocorriam à sua época e expõe via a literatura ao afirmar que

\begin{abstract}
fazer forçosamente em minha vida e com alguma atitude a felicidade ao menos uma criatura, só que na prática, isto é, de fato, eu colocaria como mandamento para todo e qualquer homem avançado, assim como faria constar numa lei ou tornaria obrigação, que todo homem deveria plantar ao menos uma árvore durante a vida, tendo em vista o desflorestamento da Rússia; aliás, só uma árvore seria pouco, seria possível ordenar o plantio de uma árvore por ano. (DOSTOIÉVSKI, 2015, p. 497)
\end{abstract}

Percebia o literato o que estava a se passar em solo russo com a retirada de árvores para a montagem das primeiras fábricas da nascente indústria. Mas, tal ato, estava por causar um impacto ambiental visto pelo escritor que aponta, de forma objetiva, para o culpado: o homem. Estabelece, ainda, que caso pudesse estipularia a pena de que cada um plantasse uma árvore por ano. Dostoiévski não estava a discutir sustentabilidade, mas percebia o necessário equilíbrio homem e natureza sendo rompido pela atividade cultural capitalista.

Adentramos ao Séc. XXI e o impacto ambiental causado pelo crescimento econômico desenfreado é percebido, cada vez mais, na economia, no direito, nas ciências sócias, na saúde humana, no aquecimento global e se percebe a necessidade de retomar a discussão em torno de um meio termo, de um equilíbrio ambiental.

Thomas \& Callan aludem que o desequilíbrio ambiental fruto do rompimento do elo homem e natureza aumenta à "medida que a sociedade mudou com o passar do século XXI, ela agora enfrenta um importante desafio: proteger e preservar os recursos do planeta conforme continua a se desenvolver economicamente. " (THOMAS \& CALLAN, 2014, p. 13) 
Outro problema a ser apresentado, por também afetar a relação homem e meio ambiente, reside na distância entre o conhecimento e o pensamento conforme apontado por Arendt (2014) ao afirmar que

\begin{abstract}
se for comprovado o divórcio entre o conhecimento (no sentido moderno do de conhecimento técnico [know-how]) e o pensamento, então passaríamos a ser, sem dúvida, escravos indefesos, não tanto de nossas máquinas quanto de nosso conhecimento técnico, criaturas desprovidas de pensamento à mercê de qualquer engenhoca tecnicamente possível, por mais mortífera que seja." (ARENDT, 2014, p. 4)
\end{abstract}

Este homem, ao qual alude Hannah Arendt, perdeu a noção do meio termo em seu sentido aristotélico e pensa na ausência de finitude dos recursos naturais e sem preocupação com a geração presente e, muito menos, com as futuras gerações ou em um meio ambiente ecologicamente equilibrado. $\mathrm{O}$ individualismo crescente na sociedade contemporânea impede de que o homem avance à condição de cidadão e não perceba a existência dos demais seres vivos. Tal fato independe de ser a questão ambiental sendo um direito de solidariedade por perpassar em torno da cidadania não exercida. Ainda em relação à preocupação com o futuro reconhecemos a importância do exposto por Dworkin (2009) ao alegar que nossa “preocupação com as gerações futuras não é, em absoluto, uma questão de justiça, mas sim de nosso sentimento instintivo de que tanto o florescimento quanto a sobrevivência do ser humano têm uma importância sagrada. ” (DWORKIN, 2009, p. 108)

Por este ângulo o homem vai construindo para si, em termos de vida, o que Hobbes (1988) apontou ao afirmar que "a vida do homem é solitária, pobre, sórdida, embrutecida e curta. " (HOBBES, 1988, p. 76) O pensamento hobbesiano é cabível no atual momento porque a cada dano ambiental, a cada impacto ambiental, a cada crime ambiental, tornamos nossas vidas mais pobres e sórdidas. Além de, ao atingirmos a saúde humana, assumimos compromissos individuais com a obrigação de tratamento de saúde e forçamos o Estado a mais gastos na área da saúde. Abandonamos a precaução e a prevenção.

E, não fosse isso o bastante, encurtamos nossa vida, em seu sentido biológico, pelo fato que não existem condições de sobreviver, quando muito viver, em uma área denominada Terra sem preservação ou utilização com responsabilidade dos recursos naturais. Falta, ainda, ao homem a compreensão do alegado por Sen (2010) da "necessidade de ir além das regras de mercado" (SEN, 2010, p. 342). Tal situação aponta para o fato de que a questão ambiental não pode ser tratada apenas pelas questões mercadológicas sob pena de perdermos, mais do que já 
perdemos, em termos de um meio ambiente ecologicamente equilibrado consoante preceitua a Lei Maior em seu Art. 225.

$\mathrm{O}$ entendimento do que venha a ser equilíbrio ambiental deve ser visto a partir do aspecto legal e doutrinário. A Lei 6.938/81 intitulada de Política Nacional de Meio Ambiente, em seu Art. 3", I afirma ser meio ambiente "o conjunto de condições, leis, influências e interações de ordem física, química e biológica, que permite, abriga e rege a vida em todas as suas formas. " (BRASIL, Lei 6.938/81)

Considerando que estas interações interferem na vida em todas as suas formas temos, então, a presença da vida humana. Neste sentido caberia ao homem reaver e manter o equilíbrio ambiental como forma de construir, pelo aspecto legal, o espaço humano em sua relação com o meio ambiente e os recursos naturais. O mesmo diploma legal, em seu Art. $4^{\circ}$, I, esculpe como um de seus objetivos a possibilidade "à compatibilização do desenvolvimento econômico-social com a preservação da qualidade do meio ambiente e do equilíbrio ecológico. "(BRASIL, Lei 6.938/81). Discorrendo sobre a Política Nacional de Meio Ambiente, mais especificamente sobre os objetivos do supracitado diploma legal, Silva (2013) aduz que

\footnotetext{
a compatibilização do desenvolvimento econômico-social com a preservação da qualidade do meio ambiente e do equilíbrio ecológico. A conciliação dos dois valores consiste, assim, nos termos deste dispositivo, na promoção do chamado desenvolvimento sustentável, que consiste na exploração equilibrada dos recursos naturais. (SILVA, 2013, p. 27)
}

O que vem a corroborar com o exposto anteriormente de que a questão ambiental não pode ser trabalhada, discutida, sem considerar o elemento de evolução do capitalismo e a degradação ambiental crescente. Ainda mais, a preocupação legal em estabelecer ditames normativos à promoção do desenvolvimento sustentável consistindo o mesmo na exploração equilibrada dos recursos naturais.

Na mesma linha de raciocínio é importante trazer à tona a preocupação do constituinte originário com a questão ambiental ao esculpir no Art. 225 da Constituição Federal que "todos têm direito ao meio ambiente ecologicamente equilibrado, bem de uso comum do povo e essencial à sadia qualidade de vida, impondo-se ao Poder Público e à coletividade o dever de defende-lo e preservá-lo para as presentes e futuras gerações. " (CRFB/1988). O texto constitucional pátrio afirmou o Direito Ambiental como intergeracional, transindividual, 
difuso e caracterizou a sustentabilidade dentro dos ditames constitucionais. Neste sentido Silva (2013) expõe que quando "o art. 225 da CF impõe ao Poder Público e à coletividade o dever de defender o direito ao meio ambiente ecologicamente equilibrado "para as presentes e futuras gerações" está precisamente dando o conteúdo essencial da sustentabilidade. " (SILVA, 2013, p. 28)

E o supracitado autor aduz que "o desenvolvimento não elimina a pobreza absoluta, não propícia um nível de vida que satisfaça as necessidades essenciais da população em geral, ele não pode ser qualificado como sustentável. " (SILVA, 2013, p. 28) A preocupação já havia sido exposta na Conferência do Rio sobre Meio Ambiente e Desenvolvimento em 1992 quando dos 20 anos da Conferência de Estocolmo realizada em 1972. O supracitado evento trouxe em seu Princípio 5 a imposição de cooperação entre os estados conforme o afirmado de ser obrigação

\footnotetext{
"para todos os Estados e todos os indivíduos, como requisito indispensável para o desenvolvimento sustentável, irão cooperar na tarefa essencial de erradicar a pobreza, a fim de reduzir as disparidades de padrões de vida e melhor atender às necessidades da maioria da população do mundo.” (ONU, 1992)
}

E no Princípio 8 da Carta supracitada temos as obrigações postas em relação aos estados signatários de que "para alcançar o desenvolvimento sustentável e uma qualidade de vida mais elevada para todos, os Estados devem reduzir e eliminar os padrões insustentáveis de produção e consumo, e promover políticas demográficas adequadas. ” (ONU, 1992)

Ademais isso, temos que no campo constitucional pátrio, na legislação infraconstitucional nacional, nos documentos internacionais dos quais o Brasil é signatário e no terreno doutrinário nacional e/ou internacional não se admite o desenvolvimento sem considerar melhoras na qualidade de vida das pessoas e racionalidade no uso dos recursos naturais como forma de construir um desenvolvimento econômico nacional sustentável. Entretanto, como bem alega Sarlet (2014) “de lá para cá, tanto a degradação do ambiente quanto a desigualdade social apenas foram agravadas. " (SARLET, 2014, p. 115) O que reforça a premissa da necessária recuperação do homem como cidadão. Ainda no esteio do pensamento do autor em comento é necessário a

compreensão integrada dos direitos sociais e da proteção do ambiente, mediante a formatação dos direito fundamentais socioambientais, constitui um dos esteios da noção de desenvolvimento sustentável no âmbito do Estado Socioambiental de Direito. (SARLET, 2014, p. 119) 
Vê-se, desta forma, que diante o exposto por Sarlet (2014) de termos "como premissa ao desfrute de uma vida digna, estão a qualidade, a segurança e o equilíbrio ambiental. " (SARLET, 2014, p. 45) O que impõe ao Estado e à coletividade, consoante o disposto no Art. 225/CRFB/88, da procura pela sustentabilidade e do desenvolvimento nacional conforme Art. $3^{\circ}$, II, da Lei Fundamental tratando de forma diversa de acordo com o preceituado no Art. 170, VI da Lei Maior.

\section{O DESENVOLVIMENTO SUSTENTÁVEL E A QUESTÃO ÉTICA}

No sentido do exposto até o presente devemos considerar o desenvolvimento como elemento humano e que contém, em si, dignidade. Por este ângulo o desenvolvimento deve ser visto no mundo dos valores por carregar consigo a capacidade humana de (sobre) vivência.

Deve-se perceber o homem como parte do meio ambiente natural, do trabalho, construído, cultural e digital e somente assim pode ser percebido. Portanto, quando se fala em meio ambiente ecologicamente equilibrado a referência ao homem e à dignidade é direta. $\mathrm{O}$ pensamento kantiano permite entender a interconexão entre o homem e o meio ambiente e que devem ser valorados na concretização da qualidade de vida preceituada no texto constitucional. Wolkmer \& Pimmel (2013) assinalam o quanto é imperioso trazer à tona a discussão sobre

\footnotetext{
a importância de reconectar a natureza e a cultura, numa visão complementar de todos os seres vivos, envolvendo a perspectiva do Bem Viver vinculada aos Direitos da Natureza significa estabelecer estratégias ontológicas-políticas de transição até um pluriverso com novos horizontes de sentido para a vida. (WOLKMER \& PIMMEL, 2013)
}

Vê-se que o elemento cultura está posto como o papel transformador do homem em relação aos recursos naturais. A transformação do meio ambiente a partir da força transformadora do homem é impregnada de traços culturais. Situação demonstrada nas diversas formas em que os recursos naturais são utilizados de formas diversas nas mais longínquas regiões do planeta, ainda habitável, Terra.

Para entender a relação entre desenvolvimento sustentável, sustentabilidade e ética ocorre ser necessário entender que qualquer transformação no meio ambiente envolve o papel humano e é, por sua natureza, ética. Aristóteles (2010) expõe que "muitas são as ações, artes e 
ciências, muitas também são suas finalidades. O fim da medicina é a saúde, o da construção naval é um navio, o da estratégia militar é a vitória, e o da economia é a riqueza. " (Aristóteles, 2010, p. 13). Ou seja, podemos atingir o desenvolvimento dependendo com qual fim transformamos o meio em seu sentido ambiental.

A forma, desde que seja racional, com que utilizamos os recursos naturais disponíveis.

Percebe-se, portanto, que o desenvolvimento e a questão ambiental expõem uma nova discussão ética ao Direito que perpassa pelos fundamentos constitucionais e nos aproxima, cada vez mais, das questões filosóficas. Neste esteio nos encontramos diante de um novo imperativo ético: a preservação ambiental - que é uma discussão global - como caminho à realização da saúde, esteio da vida, enquanto direito constitucional fundamental.

Deve-se, entretanto, trabalhar objetivos que, conforme Thomas \& Callan (2010) devem ser considerados como objetivos universais posto que, "hoje, praticamente toda decisão sobre meio ambiente é guiada pelo que se tornou um objetivo global: qualidade ambiental, desenvolvimento sustentável e biodiversidade." (THOMAS \& CALLAN, 2010, p. 23) Para os autores supracitados qualidade ambiental vem a ser "uma redução da contaminação antropogênica a um nível que seja "aceitável” pela sociedade" (THOMAS \& CALLAN, 2010, p. 23), enquanto que desenvolvimento sustentável é a "gestão dos recursos planetários de forma que a qualidade e abundância estejam asseguradas para as gerações futuras no longo prazo" (THOMAS \& CALLAN, 2010, p. 24). E, por fim, a biodiversidade deve ser vista como "a variedade de espécies distintas, sua variabilidade genética e a diversidade dos ecossistemas que habitam" (THOMAS \& CALLAN, 2010, p. 24). Em todas as conceituações postas o ser humano tem a sua qualidade de vida pensada. Ao tempo que guardam relação direta com o tecido jurídico pátrio.

Imprescindível é resgatar o pensar ético atrelado à cidadania para elevar o homem à maioridade kantiana. Neste caminhar expõe Kant (2008) que

no reino dos fins, tudo tem ou um preço ou uma dignidade. Quando uma coisa tem um preço, pode ser substituída por algo equivalente: por outro lado, a coisa que se acha acima de todo preço, e por isso não admite qualquer equivalência, compreende uma dignidade. (KANT, 2008, p. 65)

Ocorre que o meio ambiente, enquanto direito fundamental, intergeracional, transindividual e difuso não pode ser precificado devido à carga valorativa que carrega enquanto elemento alicerce à vida da pessoa humana, não desconsiderando a dignidade das 
pessoas não humanas. Por este ângulo comungamos do pensamento de Sarlet (2014) quando discorre sobre a dimensão ecológica da dignidade da pessoa humana e alega que

\begin{abstract}
em suma, o que se afirma é que a partir do princípio constitucional da dignidade da pessoa humana, embora no mais das vezes em articulação com outros valores e bens jurídicos-constitucionais, projeta-se todo um leque de posições jurídicas subjetivas e objetivas, com a função precípua de tutelar a condição existencial humana contra quaisquer violações do seu âmbito de proteção, assegurando o livre e pleno desenvolvimento da personalidade de cada ser humano." (SARLET, 2014, p. 79)
\end{abstract}

A degradação do meio ambiente, o dano ambiental, o crime ambiental ou a não efetivação do disposto no Art. 225/CRFB/88 não se trata de descumprimento de questões insculpidas no texto constitucional. São, antes de tudo, uma ruptura com questões éticas e filosóficas. Quando não consigo olhar para o Outro, no sentido de alteridade, não estou a agir de forma ética. E, dentro do aqui exposto, o Outro é o meio ambiente natural que vem a ser condição sine qua non à sobrevivência humana. Aduz retornar à construção teórica de Silva (2014) ao afirmar que

a qualidade do meio ambiente transforma-se, assim, num bem ou patrimônio, cuja preservação, recuperação ou revitalização se tornaram um imperativo ao Poder Público, para assegurar uma boa qualidade de vida, que implica boas condições de trabalho, lazer, educação, saúde, segurança - enfim, boas condições de bem-estar do homem e de seu desenvolvimento. (SILVA, 2014, p. 541)

O bem-estar exposto por Silva (2014) guarda relações com o Bem Viver de Thomas \& Callan (2010) quando ambos retomam a expressão qualidade de vida a partir do uso racional dos recursos naturais ou, caso queiramos utilizar a classificação doutrinária de meio ambiente natural, do trabalho, cultural, artificial e digital. E para especificar ainda mais a relação ética entre o meio ambiente, o fundamento da dignidade da pessoa humana faz-se necessário expor a definição jurídica de bem ambiental que consoante Fiorillo (2016) está

\footnotetext{
por via de consequência vinculada não só à tutela da vida da pessoa humana mas particularmente à tutela da vida da pessoa humana com dignidade, remetendo o intérprete ao conceito doutrinário de piso vital mínimo, sendo certo que as ações ambientais serão via de regra destinadas à tutela de referido bem apontado no art. 225 da Constituição Federal." (FIORILLO, 2016, p. 69)
}

Vê-se, portanto, da impossibilidade de uma discussão relativa ao meio ambiente, desenvolvimento econômico, sustentabilidade sem a presença do falar ética e ao mesmo tempo alertarmos para a ausência de uma "consciente conversão ética, direcionada à proteção 
do ambiente, não haverá alternativa para o habitante deste planeta injuriado. " (NALINI, 2015, p. 51).

Ademais, faz-se importante destacar o prescrito na Lei Maior, em seu Art. 170, VI, de que a "defesa do meio ambiente, inclusive mediante tratamento diferenciado conforme o impacto ambiental dos produtos e serviços e de seus processos de elaboração e prestação." (BRASIL, 1988). De vital importância à compreensão do referido artigo e inciso na relação sobre o desenvolvimento posto no texto constitucional ser sustentável, ético e, ainda, trazer consigo a ideia imprescindível de sustentabilidade enquanto política de desenvolvimento nacional procurando construir a qualidade de vida essencial ao Ser Humano.

\section{CONSIDERAÇÕES FINAIS}

O término do presente construto teórico fortaleceu a convicção da impossibilidade concreta de quem pensa o Direito no Séc. XXI conseguir elaborar ideias a partir somente dos conhecimentos adquiridos no terreno legal. Primeiro devemos partir da premissa de que nenhuma construção legal é meramente legal. É, antes de tudo, moral, ética e filosófica. O debate estabelecido ao longo destas linhas confirmou a premissa de que o Direito Ambiental somente pode ser compreendido no âmbito jurídico dentro de uma leitura sistêmica do Direito devido à sua condição de direito fundamental.

Leitura esta que deve perpassar pela elaboração filosófica da dignidade da pessoa humana no pensamento kantiano, pela Revolução Industrial, a evolução do capitalismo até as primeiras preocupações jusfilosóficas de que o Estado deve regular a atividade econômica à ótica do crescimento econômico, em um primeiro momento, para um pensar no desenvolvimento econômico que na década de 1970 foi denominado de desenvolvimento econômico sustentável.

Percebeu-se, ainda, a possibilidade da construção de uma existência digna na seara da dignidade da pessoa humana, fundamento constitucional. Confirmou-se a necessária interpretação da Lei Maior como esteio à garantia da pessoa humana a ter acesso à sadia qualidade de vida. Bem como o necessário resgate do homem do habitat distante da prática cidadã.

No esteio do fundamento da dignidade da pessoa humana, elaboração teórica de base kantiana que foi esculpida como alicerce da Lei Maior Pátria, ficou clarificado a extensão de 
tal recorte filosófico para além da pessoa em seu sentido humano para a necessária valoração do meio ambiente retirando-o do processo de precificação em que foi posto pelas décadas seguidas de exploração econômica em nome do crescimento econômico, ou mesmo do desenvolvimento que não conseguiu atingir as pessoas no concernente à melhoria da qualidade de vida.

Demonstrou-se, de forma legal e doutrinária, que não existe desenvolvimento econômico que não seja sustentável e, ainda mais, que não atenda a vida do ser humano na melhoria da sua vivência na Terra. Em outras palavras, somente teremos desenvolvimento nacional econômico sustentável quando as condições de vida das pessoas forem transformadas para melhor,

Por fim, demonstrou-se que o processo de não atendimento aos fundamentos e objetivos constitucionais atinge o homem em sua essência e este não percebe tal fato devido a resistir em chegar à maioridade no sentido kantiano. Comprovou-se, neste diapasão, da impossibilidade de avançarmos na superação da crise ambiental em que estamos inseridos sem consideramos as questões éticas, a importância da sustentabilidade, a dignidade da pessoa humana e o resgate do homem para colocá-lo novamente na condição de cidadão.

\section{REFERÊNCIAS}

ALEXY, Robert. Conceito e validade do direito. São Paulo, Editora WMF Martins Fontes, 2009

Teoria dos direitos fundamentais. $2^{\mathrm{a}}$ Ed. São Paulo, Malheiros Editores Ltda, 2012.

Direito, razão, discurso: estudos para a filosofia do direito. Porto Alegre, Livraria do Advogado Editora, 2010.

ARENDET, Hannah. A condição humana. 12. ed. rev. Rio de Janeiro, Forense Universitária, 2014. 
ARISTÓTELES. Ética a nicômaco. São Paulo, Martin Claret, 2003.

BARBIERI, José Carlos. Desenvolvimento e meio ambiente: as estratégias de mudanças da agenda 21. 15 a ed. Petrópolis, Vozes, 2014.

BENFATTI, Fabio Fernandes Neves. Direito ao desenvolvimento. São Paulo, Saraiva, 2014.

BERCOVICI, Gilberto. Constituição econômica e desenvolvimento: uma leitura a partir da constituição de 1988. São Paulo, Malheiros Editores, 2005.

BRASIL. Constituição (1988). Constituição da república federativa do brasil. Brasília: Senado Federal, Subsecretaria de Assuntos Técnicos, 2008.

BORON, Atílio. Estado, capitalismo e democracia na América Latina. São Paulo, Paz e Terra, 1994.

BRUM, Argemiro J. O desenvolvimento econômico brasileiro. $15^{\text {a }}$ Ed. Petrópolis, 1995.

CANOTILHO, J. J. Gomes, CORREIA, Marcus Orione Gonçalves, CORREIA, Erica Paula Barcha. Direitos fundamentais sociais. $2^{\circ}$ ed. São Paulo, Saraiva, 2015.

CERQUEIRA, Marcello. A Constituição na história: origem e reforma: da revolução inglesa de 1640 à crise do leste europeu. $2^{a}$ Ed. rev. e ampl. até a EC no 52/2006 - Rio de Janeiro, Editora Revan, 2006.

MEDAUAR, Odete. (Organização). Coletânea de legislação ambiental. 14 ${ }^{\mathrm{a}}$ ed. São Paulo, Editora Revista dos Tribunais, 2015.

DOSTOIÉVSKI, Fiódor. O adolescente. São Paulo, Editora 34, 2015. 
DWORKIN, Ronald. O domínio da vida. $2^{\mathrm{a}}$ ed. São Paulo, Editora WMF Martins Fontes, 2009.

FIORILLO, Celso Antonio Pacheco. Princípios do direito processual ambiental. $6^{\mathrm{a}} \mathrm{ed}$. São Paulo, Saraiva, 2016.

FRIEDE, Reis. Ciência do direito, norma, interpretação e hermenêutica jurídica. $8^{\mathrm{a}}$ Ed. Rio de Janeiro, Forense, 2011.

GOZZO, Débora.; LIGIERA, Wilson Ricardo. (Organizadores) Bioética e direitos fundamentais. São Paulo, Saraiva, 2012.

GRAU, Eros Roberto. A ordem econômica na constituição de 1988 (interpretação e crítica). 17ª ed, São Paulo, Malheiros Editores, 2015.

HOBBES. Vida e Obra. Coleção os pensadores. São Paulo, Editora Nova Cultural, 1988.

KANT, Immanuel. Fundamentação da metafísica dos costumes e outros escritos. São Paulo, Martin Claret, 2008.

Crítica da razão pura. Lisboa, Edição da Fundação Calouste

Gulbenkian, 2001

Introdução ao estudo do direito. Bauru, EDIPRO, 2007.

NALINI, José Renato. Ética ambiental. $4^{\text {a }}$ Ed. rev. e ampl. São Paulo, Revista dos Tribunais, 2015.

NUSSBAUM, Martha. Fronteiras da justiça: deficiência, nacionalidade, pertencimento à espécie. São Paulo, Editora WMF Martins Fontes, 2013. 
ORGANIZAÇÃO DAS NAÇÕES UNIDAS. Declaração do rio sobre meio ambiente e desenvolvimento. Junho de $1992 . \quad$ Disponível em <http://www.onu.org.br/rio20/img/2012/01/rio92.pdf> Acesso em: 07 de agosto de 2016.

PIOVESAN, Flavia. Temas de direitos humanos. $4^{\mathrm{a}}$ ed. São Paulo, Saraiva, 2010.

POSNER, Richard A. Fronteiras da teoria do direito. São Paulo, Editora WMF Martins Fontes, 2011.

RAZ, Joseph. Uma discussão sobre a teoria do direito. Joseph Raz, Robert Alexy, Eugenio Buygin. Trad. Sheila Stolz. São Paulo, Marcial Pons, 2013.

SACHS, Ignacy. Desenvolvimento includente, sustentável, sustentado. Rio de Janeiro, Garamond, 2004.

SACHS, Jeffrey. O fim da pobreza: como acabar a miséria mundial nos próximos vinte anos. São Paulo, Companhia das Letras, 2005.

SARLET, Ingo Wolfgang. A eficácia dos direitos fundamentais. $7^{\text {a }}$ Ed. rev. atual. e ampl. Porto Alegre, Livraria do Advogado, 2007.

Dignidade (da pessoa) humana e direitos fundamentais na constituição federal de 1988. 10 ed. Porto Alegre, Livraria do Advogado, 2015.

SARLET, Ingo Wolfgang; FENSTERSEIFER, Tiago. Direito constitucional ambiental. São Paulo, Editora Revista dos Tribunais, 2014.

SCHWARTZ, Germano. O tratamento jurídico do risco no direito à saúde. Porto Alegre, Livraria do Advogado editora, 2004.

SEN, Amartya. Desenvolvimento como liberdade. São Paulo, Companhia das Letras, 2010.

SILVA, José Afonso da. Teoria do conhecimento constitucional. São Paulo, Malheiros Editores Ltda., 2014. 
Direito Ambiental Constitucional. 10ª Ed. São Paulo, Malheiros, 2013

SILVA, Virgílio Afonso da. Direitos fundamentais: conteúdo essencial, restrições e eficácia. $2^{\mathrm{a}}$ Ed. São Paulo, Malheiros Editores Ltda.,

THOMAS, Janet M.; CALLAN, Scott J. Economia ambiental: fundamentos, políticas e aplicações. São Paulo, Cengage Learning, 2014.

THOMPSON, E. P. Costumes em comum. São Paulo, Companhia das Letras, 1998.

VEIGA, José Eli da. Desenvolvimento sustentável: o desafio do século XXI. Rio de Janeiro, Garamond, 2010.

2015.

. Para entender o desenvolvimento sustentável. São Paulo, Editora 34,

WOLKMER, Maria de Fátima S.; PIMMEL, Nicole Freiberger. Política nacional de recursos hídricos: governança da água e cidadania ambiental. Florianópolis, Sequência, Dez. 2013. Disponível em: https://periodicos.ufsc.br/index.php/sequencia/article/view/30850. Acesso em: 07 agosto. 2013. 